J. Lake Sci.(湖泊科学), 2021, 33(1): 158-167

DOI 10. 18307/2021. 0108

(c) 2021 by Journal of Lake Sciences

\title{
鄱阳湖网箱养殖区沉积物有机质来源分析
}

\author{
王毛兰**熊 金, 何 永, 赵茜宇,刘景景 \\ （南昌大学资源环境与化工学院,鄱阳湖环境与资源利用教育部重点实验室,南昌 330031)
}

\begin{abstract}
摘 要: 通过对鱼苗时期鄱阳湖网箱养殖区沉积物、饵料及鱼粪等样品总有机碳 (TOC) 含量、总氮 (TN) 含量、碳氮比 $(\mathrm{C} / \mathrm{N}) 、 \delta^{13} \mathrm{C}$ 及 $\delta^{15} \mathrm{~N}$ 的测定, 分析探讨了鄱阳湖网箱养殖区沉积物有机质来源, 量化了网箱养殖废物对养殖区沉积物有 机质的贡献. 结果表明, 网箱养殖区沉积物的 $\delta^{13} \mathrm{C}$ 和 $\delta^{15} \mathrm{~N}$ 值分别为 $-27.67 \% 0 \sim-25.65 \% 0$ 和 5.19\%0 7.27\% , 伹料的 $\delta^{13} \mathrm{C}$ 和 $\delta{ }^{15} \mathrm{~N}$ 值分别为 $-24.73 \% 0$ 和 $10.28 \%$, 鱼粪的 $\delta^{13} \mathrm{C}$ 和 $\delta^{15} \mathrm{~N}$ 值分别为 $-26.30 \% 0$ 和 $15.54 \%$. 网箱养殖区沉积物有机质来源 主要有残饵、浮游生物及其他来源, 其贡献率分别为 $48.3 \% \pm 11.4 \% 、 25.6 \% \pm 11.3 \%$ 及 $26.0 \% \pm 5.8 \%$, 而鱼粪的贡献几乎可 以忽略不计. 在水动力平流引起的扩散及沉积物的再悬浮的影响下, 网箱养殖源有机质的扩散距离达 $1500 \mathrm{~m}$. 在鱼苗时 期,鱼类网箱养殖的残饵是鄱阳湖网箱养殖区沉积物有机质的主要来源.
\end{abstract}

关键词：网箱养殖; 碳同位素;氮同位素;沉积物 ; 鄱阳湖

\section{Sources of sedimentary organic matter from the cage fish farm in Lake Poyang, China *}

\section{Wang Maolan $^{* *}$, Xiong Xin, He Chang, Zhao Qianyu \& Liu Jingjing}

(The Key Laboratory of Poyang Lake Environment and Resource Utilization Ministry of Education, School of Resources Environmental and Chemical Engineering, Nanchang University, Nanchang 330031, P.R.China)

Abstract: The content of total organic carbon (TOC), total nitrogen (TN), the $\mathrm{C} / \mathrm{N}$ ratio and the carbon and nitrogen stable isotope compositions of the sedimentary organic matter, fish feed and fish feces were measured from the cage fish farm in Lake Poyang. The origins of the sedimentary organic matter were analyzed using the carbon and nitrogen isotope compositions and $\mathrm{C} / \mathrm{N}$ ratios. The results showed that the $\delta^{13} \mathrm{C}$ and $\delta^{15} \mathrm{~N}$ values of sediments ranged from $-27.67 \%$ to $-25.65 \%$ and from $5.19 \%$ to $7.27 \%$, respectively. The $\delta^{13} \mathrm{C}$ values of waste feed and fish feces were $-24.73 \%$ and $-26.30 \%$, respectively. And the $\delta^{15} \mathrm{~N}$ values of waste feed and fish feces were $10.28 \%$ and $15.54 \%$, respectively. The sedimentary organic matter of the cage fish farm had a mixed source of waste feed, plankton, and the other organic matter. The mean proportions of the waste feed, plankton, and the other organic matter were $48.3 \% \pm 11.4 \%, 25.6 \% \pm 11.3 \%$, and $26.0 \% \pm 5.8 \%$. The contribution of fish feces to the sedimentary organic matter pool was insignificant. The waste feed seemed to disperse about $1500 \mathrm{~m}$ distance from the cage under the influence of the dispersion and resuspension. During the period of fry, the waste feed of cage fish culture was the main source of the sedimentary organic matter in the cage fish farm area of Lake Poyang.

Keywords: Cage fish culture; carbon isotope; nitrogen isotope; sediment; Lake Poyang

鱼类网箱养殖是一种高密度、集约化的养殖方式, 饵料是它主要的能量来源, 经过长期养殖, 残饵、粪便 等养殖废物在养殖区大量积累, 使得养殖区水体及沉积物营养盐和有机物含量增加, 从而导致了养殖水域 的有机污染和富营养化 ${ }^{[1-5]}$. 沉积物作为网箱养殖生态系统的一个重要组成部分, 直接影响着上层水质和养 殖生物的健康. 网箱养殖对沉积物最明显的影响在于有机物的积累及底质向缺氧状态的改变, 残旿与鱼粪 是养殖区沉积物有机质的主要组成部分 ${ }^{[6]}$, 养殖水体沉积物总有机碳和总氮的释放量比自然过程 (如矿化

* 2019-12-06 收稿;2020-04-24 收修改稿.

国家自然科学基金项目 (41663004)、国家水体污染控制与治理科技重大专项 (2017ZX07301002-05) 和南昌大学鄱 阳湖环境与资源利用教育部重点实验室开放基金项目 (PYH2015-02) 联合资助.

** 通信作者; E-mail:wml2001@163.com. 
作用、反硝化作用等) 显示的数值分别高 2.5 和 2.2 倍 ${ }^{[7]}$. 沉积物中高含量的营养盐和有机物在一定条件下 会重新释放到水体中, 造成水体“二次污染” ${ }^{[8]}$.

目前的研究大多集中在利用沉积物的化学指标 (如硫化物、氮、磷、有机质含量等)、生物指标 (底栖生物 种类等) 来定性描述网箱养殖对沉积环境的影响 ${ }^{[2,5,9-13]}$, 而定量化描述网箱养殖污染物对沉积物中有机质

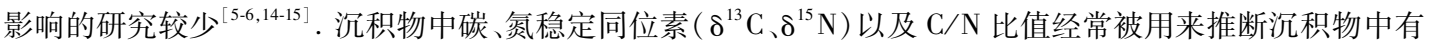
机质的来源, 这些示踪是建立在不同来源的有机质有不同的 $\mathrm{C} / \mathrm{N}$ 比值和稳定同位素组成基础上的 ${ }^{[16-18]}$. 将 碳、氮稳定同位素应用于养殖水体沉积物有机质来源的研究近期也得到较快的发展 ${ }^{[5-6,14-15]}$, 而这些研究大 多集中在海水网箱养殖区,对于淡水网箱养殖区的研究非常少.

鄱阳湖是我国最大的淡水湖,拥有丰富的水产资源. 鄱阳湖都昌水域曾发展网箱养殖 1 万余箱, 面积近

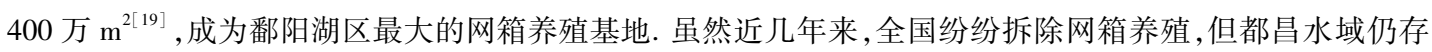
在大面积网箱养殖, 直至 2017 年底, 鄱阳湖都昌水域网箱养鱼面积有约 1 万 $\mathrm{m}^{2[20]}$, 到 2019 年鄱阳湖才全面 取缔网箱养殖. 需要指出的是, 多年网箱养殖产生的养殖废物对养殖区沉积物及水环境的影响是个长久的 过程, 并不会因为网箱养殖的停止而立即消失, 残留在沉积物中的养殖废物仍会不断地释放到水环境中而 影响养殖区的水环境质量. Wang 等 ${ }^{[21]}$ 对重庆长寿湖的研究表明, 由于网箱养殖期间沉积于湖底的鱼饲料及 养殖废物的再释放, 使得取缔网箱养殖十多年后的长寿湖仍处于中富营养状态. Xie 等 ${ }^{[22]}$ 也发现长寿湖沉 积物的重金属平均浓度在已取缔网箱养殖十多年后仍是背景值的 2 倍多. 因此尽管鄱阳湖网箱于 2019 年 已全部拆除, 但网箱养殖期间养殖废物对养殖区沉积物的影响研究仍具有十分重要的意义. 目前有关鄱阳 湖网箱养殖区养殖废物对养殖区沉积环境的影响研究很少, 利用碳氮同位素定量研究养殖废物对其沉积物 影响方面更是未见报道. 因此, 本文选取鄱阳湖都昌水域网箱养殖区为研究对象, 通过测定其网箱养殖区沉 积物有机质、残旿及鱼粪等有机碳、氮含量及其碳、氮同位素值, 利用多元混合模型定量评估网箱养殖废物 对其养殖区沉积物有机质的影响.

\section{1 材料与方法}

\section{1 研究区概况}

鄱阳湖都昌县位于鄱阳湖北岸 $\left(28^{\circ} 50^{\prime} \sim 29^{\circ} 38^{\prime} \mathrm{N}, 116^{\circ} 2^{\prime} \sim 116^{\circ} 36^{\prime} \mathrm{E}\right)$ (图 1), 地处 “五水汇一湖” 要冲, 南联五水 (赣江、抗河、信江、饶河、修水), 北通长江, 地处亚热带湿润性季风气候区, 年均气温 $17.1^{\circ} \mathrm{C}$, 年均 降水量 $1558.7 \mathrm{~mm}$. 该区域网箱养殖已有十几年的历史, 养殖品种主要有加州鲈鱼、草鱼和鳙鱼. 采样期间 研究区养殖品种只有加州鲇鱼, 网箱养殖规模约 $7200 \mathrm{~m}^{2}$, 年产量约 $250 \mathrm{t}$. 养殖所用的饵料为人工配合饲料 和小鱼饵, 当鄱阳湖区处于禁渔期时, 人工配合饲料则成为主要的饵料, 喂养采取直接将覀料投人网箱的 方式.

采样期间平均水深为 $8.6 \mathrm{~m}$, 平均流速为 $16.3 \mathrm{~cm} / \mathrm{s}$, 透明度为 $56.5 \mathrm{~cm}$. 水体 $\mathrm{pH}$ 为 7.44 , 中性偏弱碱性, $\mathrm{COD}_{\text {Мп }} 、 \mathrm{NH}_{4}^{+}-\mathrm{N} 、 \mathrm{NO}_{3}^{-}-\mathrm{N} 、 \mathrm{TN}$ 和 TP 浓度分别为 $1.11 \sim 2.58 、 0.66 \sim 1.11 、 0.72 \sim 1.01 、 1.87 \sim 2.40$ 和 $0.21 \sim 0.41$ $\mathrm{mg} / \mathrm{L}$.

\section{2 样品的采集}

2018 年 3 月对鄱阳湖都昌水域网箱养殖区沉积物、饲料及鱼粪等进行了采集,采样点见图 1. 在网箱养 殖水域沿水流方向设置采样断面, 网箱边缘 $50 \mathrm{~m}$ 内的样品定义为“网箱区”样品, 共 5 个点; 以网箱为中心, 在 $100 \sim 500 \mathrm{~m}$ 处沿水流方向断面上每 $100 \mathrm{~m}$ 设置一个采样点, $500 \sim 1100 \mathrm{~m}$ 处每 $200 \mathrm{~m}$ 设置一个采样点, $1500 \mathrm{~m}$ 处设一个采样点, 共计采样点 14 个. 在网箱边缘 $5000 \mathrm{~m}$ 处设置一个采样点作为对照点.

沉积物样品用抓斗式底泥采样器 (最大采泥深度 $10 \mathrm{~cm}$ ) 采集, 立即运回实验室冷冻干燥; 饵料向当地渔 民收集; 取 20 条个体质量 $200 \mathrm{~g}$ 左右的养殖鱼用容器单独养殖, $24 \mathrm{~h}$ 后用吸管小心收集容器底部的鱼粪.

\section{3 样品的处理及分析}

干燥后的沉积物样品研磨过 200 目笁, 研磨过篎后的样品滴加 $1 \mathrm{~mol} / \mathrm{L}$ 的盐酸浸湿, 放人盛有浓盐酸的 干燥器中反应 $24 \mathrm{~h}$ 以除去样品中的无机碳, 然后反复用蒸馏水冲洗样品直至 $\mathrm{pH}$ 为中性后再将其冷冻干燥. 覀料及鱼粪样品用 $1 \mathrm{~mol} / \mathrm{L}$ 的盐酸浸泡 $30 \mathrm{~min}$ 后, 用蒸馏水清洗至中性, 冷冻干燥, 研磨过 200 目篎 ${ }^{[6]}$. 经 
过上述处理后的样品在国家海洋局第三海洋研究所用元素分析仪 (Flash EA 1112HT) 和同位素质谱仪 (Delta $\mathrm{V}$ advantage) 联用测定 TOC、TN 含量及 $\delta^{13} \mathrm{C} 、 \delta^{15} \mathrm{~N}$ 值. $\delta^{13} \mathrm{C}$ 和 $\delta^{15} \mathrm{~N}$ 的计算公式分别为:

$$
\begin{aligned}
& \delta^{13} \mathrm{C}(\%)=\left[\left(R_{\text {sample }}-R_{\text {standard }}\right) / R_{\text {standard }}\right] \times 1000, R={ }^{13} \mathrm{C} /{ }^{12} \mathrm{C} \\
& \delta^{15} \mathrm{~N}(\%)=\left[\left(R_{\text {sample }}-R_{\text {standard }}\right) / R_{\text {standard }}\right] \times 1000, R={ }^{15} \mathrm{~N} /{ }^{14} \mathrm{~N}
\end{aligned}
$$

式中, ${ }^{13} \mathrm{C} /{ }^{12} \mathrm{C}$ 和 ${ }^{15} \mathrm{~N} /{ }^{14} \mathrm{~N}$ 分别对应于国际标准 ViennaPDB 与大气中的氮标准, 分析误差小于 $\pm 0.2 \%$.

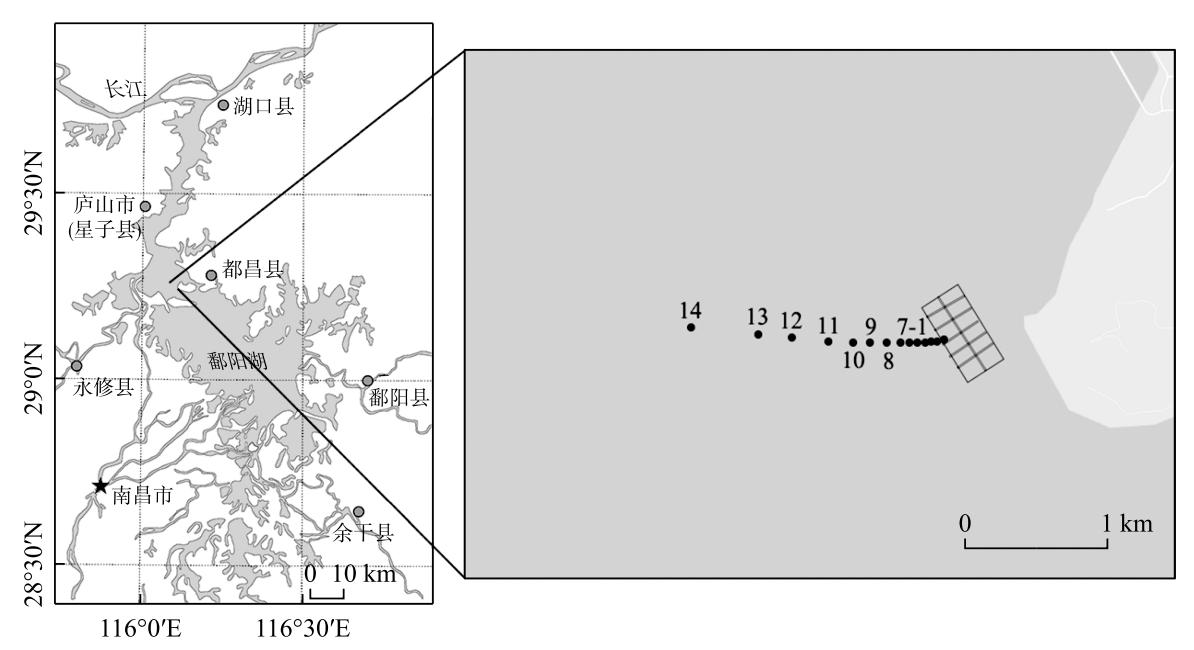

图 1 鄱阳湖网箱养殖区采样点

Fig. 1 Sampling sites of the cage fish farm in Lake Poyang

\section{2 结果与讨论}

\section{1 网箱养殖区沉积物有机碳、氮含量}

研究区沉积物 TOC、TN 含量变化范围分别为 $3.19 \sim 12.74$ 和 $0.42 \sim 1.71 \mathrm{mg} / \mathrm{g}$, 最小值均出现在离网箱最 远的 $1500 \mathrm{~m}$ 处, 最大值均出现在离网箱 $300 \mathrm{~m}$ 处, 网箱下面 $1^{\#}$ 点 TOC、TN 含量也较高, 分别为 10.51 和 1.51 $\mathrm{mg} / \mathrm{g}$ (图 2a, b). 研究区沉积物 TOC 和 TN 含量之间具有较为显著的线性关系 $\left(R^{2}=0.9690, P<0.001\right.$ ) (图 3a).

不同类型的有机质具有不同的 $\mathrm{C} / \mathrm{N}$, 因此 $\mathrm{C} / \mathrm{N}$ 可以用于判断沉积物有机质的来源 ${ }^{[17]}$. 通常认为, 陆生 高等植物的 $\mathrm{C} / \mathrm{N}$ 一般 $>15$, 水生植物的 $\mathrm{C} / \mathrm{N}$ 一般在 $10 \sim 30$ 左右 ${ }^{[23]}$, 卢风云等 ${ }^{[24]}$ 的研究得出潮白河水生维 管束植物的 $\mathrm{C} / \mathrm{N}$ 为 $12.6 \sim 18.5$; 土壤有机质的 $\mathrm{C} / \mathrm{N}$ 在 $10 \sim 13$ 之间 ${ }^{[25-26]}$, 藻类的 $\mathrm{C} / \mathrm{N}$ 一般在 $5 \sim 8$ 左右 ${ }^{[27-28]}$. 鄱阳湖网箱养殖区鱼粪 $\mathrm{C} / \mathrm{N}$ 为 5.85 , 饲料 $\mathrm{C} / \mathrm{N}$ 为 $4.36 \sim 7.22$, 沉积物 $\mathrm{C} / \mathrm{N}$ 范围为 $6.85 \sim 7.84$ (其含量随距离 变化见图 2c), 平均值为 $7.23 \pm 0.27$, 反映了鄱阳湖网箱养殖区沉积物有机质来源的混合性, 即既有外源, 也 有湖泊自身来源.

\section{2 鄱阳湖网箱养殖区沉积物碳、氮同位素特征}

2.2.1 研究区沉积物碳同位素特征研究区沉积物 $\delta^{13} \mathrm{C}$ 值范围为 $-27.67 \%$ - 25.65\% , 明显低于鄱阳湖其他 区域沉积物碳同位素值 $(-25.66 \% 0 \sim-12.56 \%)^{[17]}$, 也明显低于对照点沉积物的 $\delta^{13} \mathrm{C}$ 值 $(-25.66 \%)$. 从图 $2 \mathrm{~d}$ 可以看出研究区沉积物 $\delta^{13} \mathrm{C}$ 值具有明显的空间变化特征, $\delta^{13} \mathrm{C}$ 值最低出现在距网箱 $300 \mathrm{~m}$ 处, 其次是出现 在距网箱 $400 \mathrm{~m}$ 处, 最大值出现在距网箱 $700 \mathrm{~m}$ 处,网箱底下沉积物也具有较高的 $\delta^{13} \mathrm{C}$ 值, 为 $-25.83 \%$. 鄱 阳湖网箱养殖区沉积物 $\mathrm{C} / \mathrm{N}$ 与 $\delta^{13} \mathrm{C}$ 之间存在显著的负相关关系 $\left(R^{2}=0.2743, P<0.001\right.$ ) (图 $3 \mathrm{~b}$ ), 因此本研 究中 $\mathrm{C} / \mathrm{N}$ 能严格体现物源的影响 ${ }^{[15]}$.

2.2.2 研究区沉积物氮同位素特征研究区沉积物 $\delta^{15} \mathrm{~N}$ 值范围为 $5.19 \% 0 \sim 7.27 \%$, 总体上高于鄱阳湖其他区 域沉积物氮同位素值 $(3.72 \% 0 \sim 6.27 \%)^{[17]}$, 大部分采样点的 $\delta^{15} \mathrm{~N}$ 值高于对照点的 $\delta^{15} \mathrm{~N}$ 值 $(6.27 \% 0)$, 高 $\delta^{15} \mathrm{~N}$ 
值鱼饲料 $\left(8.01 \% 0 \sim 13.06 \%\right.$ ) 的输人是其主要原因 ${ }^{[21]}$. 从图 $2 \mathrm{e}$ 可以看出, 网箱区 $300 \mathrm{~m}$ 外沉积物 $\delta^{15} \mathrm{~N}$ 值随 距离呈总体下降的趋势, 最小值出现在距网箱 $1500 \mathrm{~km}$ 处, 最大值出现在距网箱 $300 \mathrm{~m}$ 处. 网箱区沉积物 $\delta^{15} \mathrm{~N}$ 值范围为 $6.03 \% 0 \sim 6.73 \%$, 平均值为 $6.44 \%$. 鄱阳湖网箱养殖区沉积物 $\mathrm{C} / \mathrm{N}$ 与 $\delta^{15} \mathrm{~N}$ 之间存在不显著的 正相关关系 $\left(R^{2}=0.0018, P>0.1\right)$ ( 图 3c).
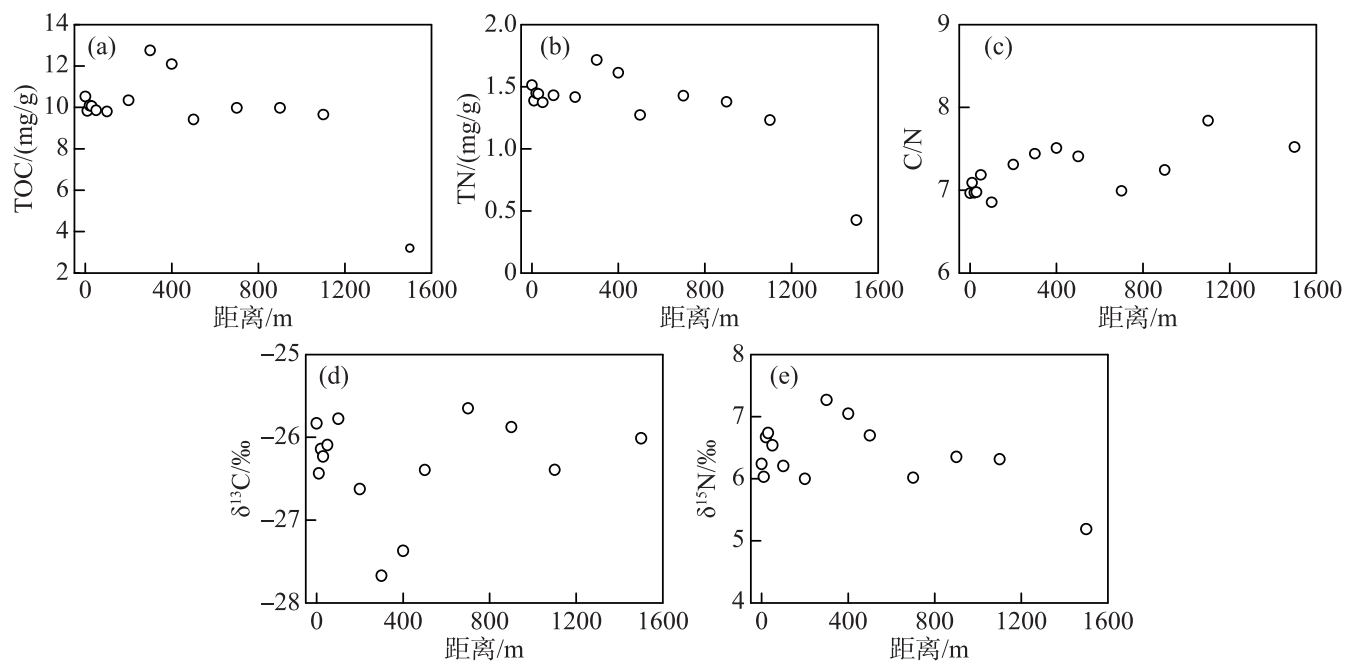

图 2 研究区沉积物总有机碳、氮及碳、氮同位素分布

Fig.2 Distribution of TOC, TN, C/N, $\delta^{13} \mathrm{C}$ and $\delta^{15} \mathrm{~N}$ in the sedimentary organic matter of the study area
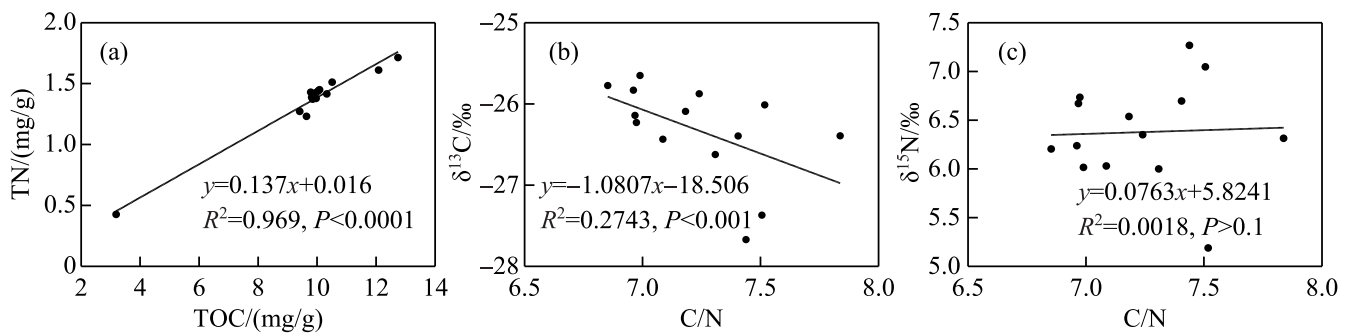

图 3 鄱阳湖网箱养殖区沉积物 TOC 与 $\mathrm{TN}(\mathrm{a}) 、 \delta^{13} \mathrm{C}$ 与 $\mathrm{C} / \mathrm{N}(\mathrm{b}) 、 \delta^{15} \mathrm{~N}$ 与 $\mathrm{C} / \mathrm{N}(\mathrm{c})$ 的关系

Fig.3 Relationship of TOC and TN $(a), \delta^{13} \mathrm{C}$ and $\mathrm{C} / \mathrm{N}(\mathrm{b}), \delta^{15} \mathrm{~N}$ and

$\mathrm{C} / \mathrm{N}(\mathrm{c})$ in the sedimentary organic matter of Lake Poyang cage fish farm

\section{3 鄱阳湖网箱养殖区沉积物有机质来源定性分析}

$\delta^{13} \mathrm{C}$ 和 $\mathrm{C} / \mathrm{N}$ 关系图是定性分析有机质来源的有效方法, 湖泊沉积物有机质的潜在来源主要包括: 陆生 高等植物 ( C3 和 C4 植物)、水生维管束植物、土壤有机质、河流浮游生物 ${ }^{[22,29]}$, 湖泊网箱养殖区沉积物有机 质的来源可能还包括鱼粪及残饵. C3 植物的 $\delta^{13} \mathrm{C}$ 值为 $-30 \% 0 \sim-23 \% 0$; 4 植物的 $\delta^{13} \mathrm{C}$ 值为 $-17 \%{ }^{2} \sim-9 \%{ }^{[30]}$; 土壤有机质的 $\delta^{13} \mathrm{C}$ 值为 $-25 \% 0 \sim-22 \%{ }^{[31]}$; 淡水水生植物的 $\delta^{13} \mathrm{C}$ 值为 $-43 \% 0 \sim-12 \%$, 大部分落在 $-28 \% 0 \sim$ $-18 \%$ 范围内 ${ }^{[32-33]}$. 卢凤云等 ${ }^{[24]}$ 的研究得出潮白河水生维管束植物的 $\delta^{13} \mathrm{C}$ 值为 $-30.0 \% \sim-16.0 \%$; 浮游植 物的 $\delta^{13} \mathrm{C}$ 值为 $-42 \% \sim-24 \%$, 平均值约为 $-30 \%{ }^{[30,34-35]}$.

鄱阳湖网箱养殖鱼粪 $\delta^{13} \mathrm{C}$ 和 $\delta^{15} \mathrm{~N}$ 分别为 $-26.30 \% 0$ 和 $15.54 \%$. 网箱养殖用到的两种饲料中人工饲料的 $\delta^{13} \mathrm{C}$ 和 $\delta^{15} \mathrm{~N}$ 分别为 $-21.41 \%$ 和 $8.01 \%$ ，小鱼饵的 $\delta^{13} \mathrm{C}$ 和 $\delta^{15} \mathrm{~N}$ 分别为 $-28.79 \% 0$ 和 $13.06 \% \%_{0}$ (表 1 ). 两种饲料 的使用比例大概为人工饲料 (干重) 占 $55 \%$, 小鱼饵占 $45 \%$, 因此养殖饲料的 $\delta^{13} \mathrm{C}$ 和 $\delta^{15} \mathrm{~N}$ 分别表示为 $-21.41 \% 0 \times 0.55-28.79 \%{ }_{0} \times 0.45=-24.73 \% 0$ 及 $8.01 \%{ }_{0} \times 0.55+13.06 \%{ }_{0} \times 0.45=10.28 \%{ }^{[6]}$. 网箱养殖区沉积物有机 
质 $\delta^{15} \mathrm{~N}$ 明显低于鱼粪和养殖饲料 $\delta^{15} \mathrm{~N}, \delta^{13} \mathrm{C}$ 明显低于养殖饲料 $\delta^{13} \mathrm{C}$, 而大部分采样点沉积物有机质的 $\delta^{13} \mathrm{C}$ 高于鱼粪 $\delta^{13} \mathrm{C}$. 研究区 $\mathrm{C} / \mathrm{N}$ 和 $\delta^{13} \mathrm{C}$ 值关系见图 4, 从图 4 可以看出, 研究区沉积物有机质来源主要有残饵、 鱼粪、湖泊浮游生物及其他来源, 而作者前期对鄱阳湖沉积物有机质来源的研究表明其主要来源为土壤有 机质、水生维管束植物及浮游生物, 且土壤有机质贡献的比例更大 ${ }^{[17]}$. 由此可看出, 网箱养殖产生的养殖废 物改变了养殖区沉积物有机质成分, 此结果可为今后的研究提供数据参考.

表 1 网箱养殖区饲料、粪便及参照点沉积物有机质碳氮同位素值

Tab. $1 \delta^{13} \mathrm{C}$ and $\delta^{15} \mathrm{~N}$ of the fish feed, fish feces in the cage fish farm and the sediment organic matter in the reference sites

\begin{tabular}{ccccc}
\hline & 人工饲料 & 小鱼饵 & 粪便 & 参照点 \\
\hline$\delta^{13} \mathrm{C} / \% 0$ & -21.41 & -28.79 & -26.30 & -25.66 \\
$\delta^{15} \mathrm{~N} / \% 0$ & 8.01 & 13.06 & 15.54 & 6.27 \\
\hline
\end{tabular}

\section{4 鄱阳湖网箱养殖区沉积物有机质来源定量分析}

为了对鄱阳湖网箱养殖区沉积有机质来源的认识更量化, 本研究结合 $\delta^{15} \mathrm{~N} 、 \delta^{13} \mathrm{C}$ 和 $\mathrm{C} / \mathrm{N}$, 使用一个四端 元混合模型来分析不同来源的贡献率. 这个模型的原理是不同端元 $\delta^{15} \mathrm{~N} 、 \delta^{13} \mathrm{C}$ 和 $\mathrm{C} / \mathrm{N}$ 在水体中的保守混合 和质量守恒定律, 基于图 4, 选定的 4 个端元分别是残饵、鱼粪、浮游生物及其他有机质. 其相应的端元混合 模型为:

$$
\begin{gathered}
\delta^{13} \mathrm{C}_{\text {Sample }}=f_{\mathrm{WF}} \cdot \delta^{13} \mathrm{C}_{\mathrm{WF}}+f_{\mathrm{FF}} \cdot \delta^{13} \mathrm{C}_{\mathrm{FF}}+f_{\mathrm{P}} \cdot \delta^{13} \mathrm{C}_{\mathrm{P}}+f_{\mathrm{R}} \cdot \delta^{13} \mathrm{C}_{\mathrm{R}} \\
\delta^{15} \mathrm{~N}_{\text {Sample }}=f_{\mathrm{WF}} \cdot \delta^{15} \mathrm{~N}_{\mathrm{WF}}+f_{\mathrm{FF}} \cdot \delta^{15} \mathrm{~N}_{\mathrm{FF}}+f_{\mathrm{P}} \cdot \delta^{15} \mathrm{~N}_{\mathrm{P}}+f_{\mathrm{R}} \cdot \delta^{15} \mathrm{~N}_{\mathrm{R}} \\
\mathrm{C} / \mathrm{N}_{\text {Sample }}=f_{\mathrm{WF}} \cdot \mathrm{C} / \mathrm{N}_{\mathrm{WF}}+f_{\mathrm{FF}} \cdot \mathrm{C} / \mathrm{N}_{\mathrm{FF}}+f_{\mathrm{P}} \cdot \mathrm{C} / \mathrm{N}_{\mathrm{P}}+f_{\mathrm{R}} \cdot \mathrm{C} / \mathrm{N}_{\mathrm{R}} \\
1=f_{\mathrm{WF}}+f_{\mathrm{FF}}+f_{\mathrm{P}}+f_{\mathrm{R}}
\end{gathered}
$$

式中, $f_{\mathrm{WF}} f_{\mathrm{FF}} f_{\mathrm{P}}$ 和 $f_{\mathrm{R}}$ 分别为鱼粪、残饵、浮游生物及其他这 4 种来源在总有机质中所占的比例; $\delta^{13} \mathrm{C}_{\mathrm{Sample}}$ 、 $\delta^{15} \mathrm{~N}_{\text {Sample }}$ 和 $\mathrm{C} / \mathrm{N}_{\text {Sample }}, \delta^{13} \mathrm{C}_{\mathrm{WF}} 、 \delta^{15} \mathrm{~N}_{\mathrm{WF}}$ 和 $\mathrm{C} / \mathrm{N}_{\mathrm{WF}}, \delta^{13} \mathrm{C}_{\mathrm{FF}} 、 \delta^{15} \mathrm{~N}_{\mathrm{FF}}$ 和 $\mathrm{C} / \mathrm{N}_{\mathrm{FF}}, \delta^{13} \mathrm{C}_{\mathrm{P}} 、 \delta^{15} \mathrm{~N}_{\mathrm{P}}$ 和 $\mathrm{C} / \mathrm{N}_{\mathrm{P}}$ 以及 $\delta^{13} \mathrm{C}_{\mathrm{R}} 、 \delta^{15} \mathrm{~N}_{\mathrm{R}}$ 和 $\mathrm{C} / \mathrm{N}_{\mathrm{R}}$ 分别表示网箱养殖区沉积物、鱼粪、残饵、浮游生物及对照点沉积物的 $\delta^{13} \mathrm{C} 、 \delta^{15} \mathrm{~N}$ 和 $\mathrm{C} / \mathrm{N}$ 值. 如 $f_{\mathrm{WF}}$ 、 $f_{\mathrm{FF}} f_{\mathrm{P}}$ 和 $f_{\mathrm{R}}$ 计算结果为负的, 则认为无贡献 ${ }^{[6]}$.

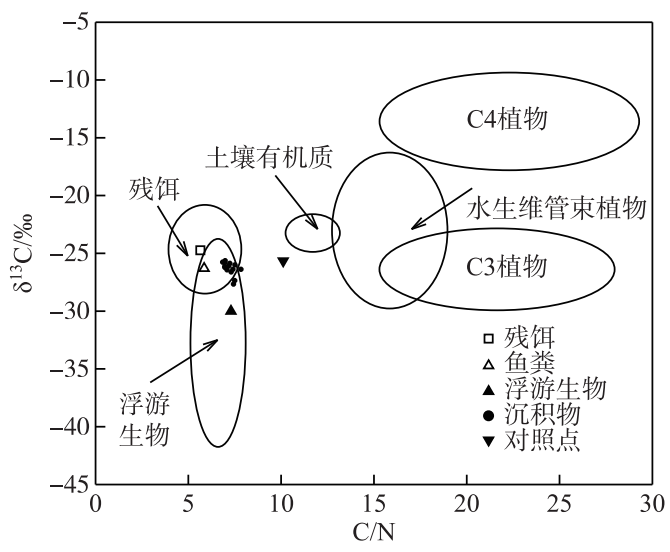

图 4 鄱阳湖网箱养殖区沉积物有机质的 $\delta^{13} \mathrm{C}$ 和 $\mathrm{C} / \mathrm{N}$ 关系

Fig.4 Relationship of $\mathrm{C} / \mathrm{N}$ and $\delta^{13} \mathrm{C}$ values from the cage fish farm sediments in Lake Poyang

残亚 $\delta^{13} \mathrm{C} 、 \delta^{15} \mathrm{~N}$ 和 $\mathrm{C} / \mathrm{N}$ 值采用前面所述方法计算所得值分别为 $-24.73 \%$ 、10.28\% 和 5.65. 本研究没有 测得浮游生物的 $\delta^{13} \mathrm{C} 、 \delta^{15} \mathrm{~N}$ 和 $\mathrm{C} / \mathrm{N}$ 值, 据 Redfield 等 ${ }^{[27]}$ 的研究证明, 淡水浮游生物同海洋浮游植物具有相 似的 $\mathrm{C} / \mathrm{N}$ 比值, 因此引用前人的研究结果, 确定浮游生物的 $\delta^{13} \mathrm{C} 、 \delta^{15} \mathrm{~N}$ 和 $\mathrm{C} / \mathrm{N}$ 值分别为 $-30 \%{ }^{[23,36]} 、 5 \% 0^{[37-38]}$ 
和 $7.3^{[39]}$.

从定量计算的结果来看 (表 2), 鄱阳湖网箱养殖区沉积物有机质主要来源为残饵、浮游生物及其他有机 质, 而鱼粪几乎无贡献, 只在距离网箱 300 和 $400 \mathrm{~m}$ 处有较低贡献, 贡献率分别为 $8.7 \%$ 和 $2.6 \%$, 因此研究区 鱼粪对网箱养殖区沉积物有机质的贡献率几乎可以忽略不计. 网箱养殖区处于主湖区, 离航道比较近, 且经 常有采砂船出现, 采砂活动有可能带走部分前几年沉积下来的养殖废物, 因此认为养殖废物对沉积物的影 响主要来源于当年的网箱养殖. 3 月正是鱼苗投放时期, 养殖鱼还比较小, 产生的粪便并不多, 湖泊的自净作 用可以将其降解, 因此鱼粪对沉积物有机质的影响不大, 而此时期投放的饲料量相对来说比较大, 残饵对养 殖区沉积物有机质的影响相对较大. 研究区水体氮、磷浓度比较高, 高营养盐水体会导致水体浮游生物量增 加, 而鲇鱼为肉食性鱼类, 并不能消耗掉增加的浮游生物, 因此沉积于湖底的浮游生物量也相应增加, 从而 使得研究区浮游生物对沉积物有机质贡献率较高.

表 2 不同来源对鄱阳湖网箱养殖区沉积物有机质的贡献率( 四端元)

Tab.2 Contribution ratios of different sources to sedimentary organic matter in cage fish farm of Lake Poyang (four endmember)

\begin{tabular}{|c|c|c|c|c|c|}
\hline 采样点 & 距离/m & $f_{\mathrm{FF}} / \%$ & $f_{\mathrm{WF}} / \%$ & $f_{\mathrm{P}} / \%$ & $f_{\mathrm{R}} / \%$ \\
\hline 1 & 0 & 85.5 & -33.6 & 27.3 & 20.8 \\
\hline 2 & 10 & 71.3 & -28.3 & 37.4 & 19.6 \\
\hline 3 & 20 & 73.7 & -23.4 & 30.4 & 19.4 \\
\hline 4 & 30 & 70.8 & -21.3 & 31.5 & 19.0 \\
\hline 5 & 50 & 70.2 & -23.6 & 28.5 & 24.9 \\
\hline 6 & 100 & 134.8 & -59.8 & -5.3 & 30.3 \\
\hline 7 & 200 & 61.3 & -24.1 & 39.0 & 23.8 \\
\hline 8 & 300 & 20.4 & 8.7 & 49.5 & 21.4 \\
\hline 9 & 400 & 27.6 & 2.6 & 45.0 & 24.9 \\
\hline 10 & 500 & 55.6 & -15.2 & 31.1 & 28.5 \\
\hline 11 & 700 & 91.2 & -38.8 & 25.1 & 22.5 \\
\hline 12 & 900 & 75.4 & -28.3 & 25.3 & 27.5 \\
\hline 13 & 1100 & 47.8 & -16.2 & 29.6 & 38.8 \\
\hline 14 & 1500 & 78.0 & -41.2 & 30.9 & 32.3 \\
\hline
\end{tabular}

为了更准确地量化残饵对网箱养殖区沉积物有机质的贡献率, 分别将 $\delta^{13} \mathrm{C}$ 与 $\mathrm{C} / \mathrm{N}, \delta^{13} \mathrm{C}$ 与 $\delta^{15} \mathrm{~N}$ 作图, 见图 5. 从图中可以看出, 网箱养殖区沉积物所有采样点的 $\mathrm{C} / \mathrm{N}$ 和 $\delta^{13} \mathrm{C}$ 都处于由残饵、浮游生物和对照点沉 积物 $\mathrm{C} / \mathrm{N}$ 和 $\delta^{13} \mathrm{C}$ 组成的三角形内 (图 5a), 而只有部分采样点的 $\delta^{13} \mathrm{C}$ 和 $\delta^{15} \mathrm{~N}$ 处于由残饵、浮游生物和对照 点沉积物 $\delta^{13} \mathrm{C}$ 和 $\delta^{15} \mathrm{~N}$ 组成的三角形内 (图 5b), 因此可以利用由 $\mathrm{C} / \mathrm{N}$ 和 $\delta^{13} \mathrm{C}$ 组成的三元线性混合模型 ${ }^{[40]}$ 来计算残饵、浮游生物和其他有机质对网箱养殖区沉积物有机质的贡献率. 其相应的线性混合模型为:

$$
\begin{gathered}
\delta^{13} \mathrm{C}_{\text {Sample }}=f_{\mathrm{FF}} \cdot \delta^{13} \mathrm{C}_{\mathrm{FF}}+f_{\mathrm{P}} \cdot \delta{ }^{13} \mathrm{C}_{\mathrm{P}}+f_{\mathrm{R}} \cdot \delta{ }^{13} \mathrm{C}_{\mathrm{R}} \\
\mathrm{C} / \mathrm{N}_{\text {Sample }}=f_{\mathrm{FF}} \cdot \mathrm{C} / \mathrm{N}_{\mathrm{FF}}+f_{\mathrm{P}} \cdot \mathrm{C} / \mathrm{N}_{\mathrm{P}}+f_{\mathrm{R}} \cdot \mathrm{C} / \mathrm{N}_{\mathrm{R}} \\
1=f_{\mathrm{FF}}+f_{\mathrm{P}}+f_{\mathrm{R}}
\end{gathered}
$$

式中, $f_{\mathrm{FF}} f_{\mathrm{P}}$ 和 $f_{\mathrm{R}}$ 分别为残饵、浮游生物和其他这 3 种来源在总有机质中所占的比例; $\delta^{13} \mathrm{C}_{\mathrm{Sample}} 、 \delta^{15} \mathrm{~N}_{\text {Sample }}$ 和 $\mathrm{C} / \mathrm{N}_{\text {Sample }}, \delta^{13} \mathrm{C}_{\mathrm{FF}} 、 \delta^{15} \mathrm{~N}_{\mathrm{FF}}$ 和 $\mathrm{C} / \mathrm{N}_{\mathrm{FF}}, \delta^{13} \mathrm{C}_{\mathrm{P}} 、 \delta^{15} \mathrm{~N}_{\mathrm{P}}$ 和 $\mathrm{C} / \mathrm{N}_{\mathrm{P}}$ 以及 $\delta^{13} \mathrm{C}_{\mathrm{R}} 、 \delta^{15} \mathrm{~N}_{\mathrm{R}}$ 和 $\mathrm{C} / \mathrm{N}_{\mathrm{R}}$ 分别表示网箱养殖区沉积 物、残饵、浮游生物及对照点沉积物的 $\delta^{13} \mathrm{C} 、 \delta^{15} \mathrm{~N}$ 和 $\mathrm{C} / \mathrm{N}$ 值. 如 $f_{\mathrm{FF}} f_{\mathrm{P}}$ 和 $f_{\mathrm{R}}$ 计算结果为负的, 则认为无贡献.

计算结果列于表 3 , 残饵对鄱阳湖网箱养殖区沉积物有机质的贡献率为 $27.0 \% \sim 61.8 \%$, 平均值为 $48.3 \%$, “网箱区” 残饵贡献率较高, 均值为 $54.5 \%$, 最大值出现在距离网箱 $100 \mathrm{~m}$ 处; 浮游生物的贡献率为 $13.0 \% \sim 52.2 \%$, 平均值为 $25.6 \%$, 而其他来源的贡献率为 $20.5 \% \sim 40.0 \%$, 平均值为 $26.0 \%$. 由此可以看出, 网 箱养殖残饵对养殖区沉积物有机质贡献较大, 且扩散范围较大, 在距离网箱最远处的 1100 和 $1500 \mathrm{~m}$ 处, 残 饵的贡献率分别为 $35.5 \%$ 和 $46.7 \%$, 也即说明网箱养殖区残饵能扩散到距网箱 $1500 \mathrm{~m}$ 处. 研究区水深为 6 
$16 \mathrm{~m}$, 水流速度为 $3.0 \sim 41.9 \mathrm{~cm} / \mathrm{s}$, 平均流速为 $16.3 \mathrm{~cm} / \mathrm{s}$, 且网箱养殖区附近经常有采砂活动. 水深和水流速 度已被认为是用模型预测养鱼场水产养殖废物扩散和排放总量的主要物理因素 ${ }^{[6,41-42]}$. Sarà 等 ${ }^{[5]}$ 研究表明, 扩散距离是水深、水流速度及养鱼场废物排放总量的函数, 沉积物再悬浮是养鱼场养殖废物扩散范围的主 要影响因素. Gondwe 等 ${ }^{[43]}$ 研究发现, 鱼粪对网箱下面沉积物的影响更小, 这主要是由于网箱养殖区水流加 速了养殖废物的有效扩散. 本研究也发现不是在网箱核心区, 而是在距离网箱 $300 \mathrm{~m}$ 处沉积物 TOC、TN 含 量最大, 这正是由于研究区水深大、水流速度快等因素加速了养殖废物的有效扩散. 因此, 水动力平流引起 的扩散及沉积物的再悬浮是鄱阳湖网箱养殖区残饵扩散距离比较远的主要原因, 此结论可为今后新兴水产 养殖选址提供科学依据.
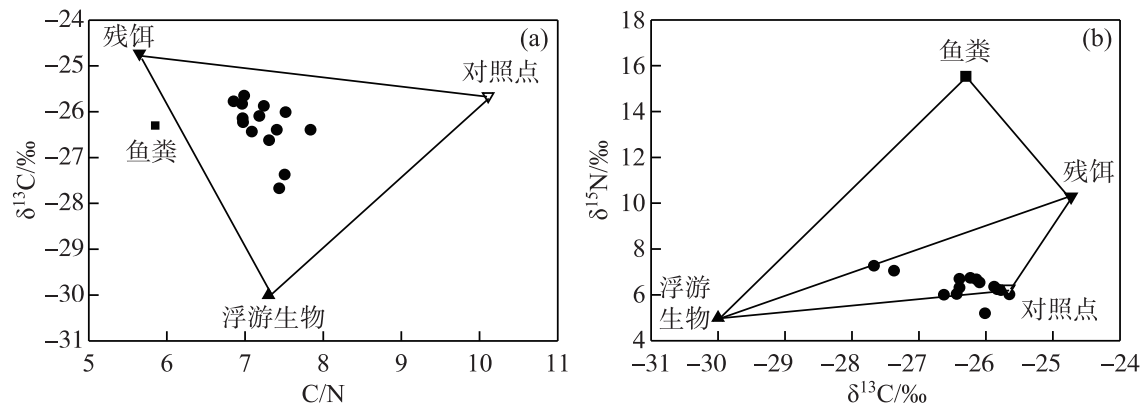

图 5 鄱阳湖网箱养殖区沉积物及其潜在来源的 $\mathrm{C} / \mathrm{N}$ 和 $\delta^{13} \mathrm{C} 、 \delta^{13} \mathrm{C}$ 和 $\delta^{15} \mathrm{~N}$ 的关系

Fig.5 Relationships of $\mathrm{C} / \mathrm{N}$ and $\delta^{13} \mathrm{C}, \delta^{13} \mathrm{C}$ and $\delta^{15} \mathrm{~N}$ in the sedimentary organic matter and the potential sources of Lake Poyang cage fish farm

表 3 不同来源对鄱阳湖网箱养殖区沉积物有机质的贡献率(三端元)

Tab.3 Contribution ratios of different sources to sedimentary organic matter in cage fish farm of Lake Poyang (three endmember)

\begin{tabular}{ccccc}
\hline 采样点 & 距离 $/ \mathrm{m}$ & $f_{\mathrm{WF}} / \%$ & $f_{\mathrm{P}} / \%$ & $f_{\mathrm{R}} / \%$ \\
\hline 1 & 0 & 60.0 & 16.9 & 23.2 \\
2 & 10 & 49.8 & 28.6 & 21.6 \\
3 & 20 & 55.9 & 23.1 & 21.0 \\
4 & 30 & 54.6 & 24.9 & 26.5 \\
5 & 50 & 52.3 & 21.2 & 21.0 \\
6 & 100 & 62.8 & 16.2 & 25.5 \\
7 & 200 & 43.0 & 31.5 & 20.8 \\
8 & 300 & 27.0 & 52.2 & 24.7 \\
9 & 400 & 29.5 & 45.8 & 29.6 \\
10 & 500 & 44.0 & 26.4 & 25.2 \\
11 & 700 & 61.8 & 13.0 & 29.5 \\
13 & 900 & 53.9 & 16.6 & 40.0 \\
14 & 1100 & 35.5 & 24.5 & 35.2 \\
\hline
\end{tabular}

残饵和鱼粪是鱼类网箱养殖过程中的主要污染来源, 据卓华龙等 ${ }^{[44]}$ 的研究, 鲇鱼对饵料的平均利用率 为 $71.8 \%$, 平均排粪率为 $6.5 \%$, 本研究显示鱼苗时期鄱阳湖网箱养殖区网箱养殖源有机物的比例为 $48.3 \% \pm$ $11.4 \%$, 其中粪便的贡献率为 0 . 因此必须提高饵料的利用率从而减少网箱养殖废物对养殖区水域环境的污 染, 实践证明改变养殖管理方式 ${ }^{[41,45]}$ 、调整网箱养殖规模及实行多类鱼种搭配混养等方法均能提高饵料的 利用率,其中改变养殖管理方式包括合理的投饲频度和投喂时间、投喂饲料颗粒大小的选择和调整、水深和 
水体理化性质的调节等.

因此, 为了减少网箱养殖废物对养殖区水域环境的影响, 促进淡水网箱养殖业的可持续发展, 在网箱养 殖过程中, 应充分提高饵料的利用率, 减少进人水体的残诐量; 科学合理地布置网箱、控制网箱规模、减少网 箱密度; 调节养殖方式、改善养殖结构, 在网箱养殖过程中做到生态养殖, 保证养殖水域生物资源环境的可 持续发展.

\section{3 结论}

网箱养殖在鄱阳湖虽已成为历史, 但本研究分析了鄱阳湖网箱养殖时期养殖区沉积物 TOC、TN 含量及 其 $\delta^{13} \mathrm{C} 、 \delta^{15} \mathrm{~N}$ 值, 揭示了网箱养殖区沉积物有机质主要来源, 并探讨了网箱养殖废物扩散距离及其主要影响 因素. 这些研究结果有助于科学评估淡水网箱养殖对养殖区水体环境的影响, 并建立科学的淡水网箱养殖 管理方式,主要研究结论如下:

1) 距离网箱 $1500 \mathrm{~km}$ 处的沉积物 TOC、TN 含量最小,而距离网箱 $300 \mathrm{~m}$ 处沉积物 TOC、TN 含量最大.

2) 鄱阳湖网箱养殖区沉积物 $\delta^{13} \mathrm{C}$ 值明显低于对照点沉积物的 $\delta^{13} \mathrm{C}$ 值; 大部分采样点 $\delta^{15} \mathrm{~N}$ 值高于对照 点的 $\delta^{15} \mathrm{~N}$ 值.

3) 有机质来源分析表明, 鱼苗时期鄱阳湖网箱养殖区沉积物有机质主要来源为残犆、浮游生物及其他, 鱼粪对网箱养殖区沉积物几乎没影响. 残饵对鄱阳湖网箱养殖区沉积物有机质的贡献率达到 $48.3 \% \pm$ $11.4 \%$.

4) 鄱阳湖网箱养殖废物能扩散到距离网箱 $1500 \mathrm{~m}$ 处, 水动力平流引起的扩散及沉积物的再悬浮是其 主要影响因素.

\section{4 参考文献}

[ 1 ] Farmaki EG, Thomaidis NS, Pasias IN et al. Environmental impact of intensive aquaculture: Investigation on the accumulation of metals and nutrients in marine sediments of Greece. Science of the Total Environment, 2014, 485/486: 554-562. DOI: $10.1016 / \mathrm{j}$.scitotenv.2014.03.125.

[ 2 ] Jan RQ, Kao SJ, Dai CF et al. Assessment of the effects of cage fish-farming on damselfish-associated food chains using stable-isotope analyses. Marine Pollution Bulletin, 2014, 86(1/2) : 111-121. DOI: 10.1016/j.marpolbul.2014.07.035.

[ 3 ] Qin DL, Jiang HF, Bai SY et al. Determination of 28 trace elements in three farmed cyprinid fish species from Northeast China. Food Control, 2015, 50: 1-8. DOI: 10.1016/j.foodcont.2014.08.016.

[ 4 ] Rubio-Portillo E, Villamor A, Fernandez-Gonzalez V et al. Exploring changes in bacterial communities to assess the influence of fish farming on marine sediments. Aquaculture, 2019, 506: 459-464. DOI: 10.1016/j.aquaculture.2019.03.051.

[ 5 ] Sarà G, Scilipoti D, Mazzola A et al. Effects of fish farming waste to sedimentary and particulate organic matter in a southern Mediterranean area (Gulf of Castellammare, Sicily) : A multiple stable isotope study $\left(\delta^{13} \mathrm{C}\right.$ and $\left.\delta^{15} \mathrm{~N}\right)$. Aquaculture, 2004, 234 : 199-213. DOI: 10.1016/j.aquaculture.2003.11.020.

[ 6 ] Yokoyama H, Abo K, Ishihi Y. Quantifying aquaculture-derived organic matter in the sediment in and around a coastal fish farm using stable carbon and nitrogen isotope ratios. Aquaculture, 2006, 254: 411-425. DOI: 10. 1016/j. aquaculture. 2005.10 .024$.

[ 7 ] Tsutsumi H, Srithongouthal S, Inoue A et al. Seasonal fluctuations in the flux of particulate organic matter discharged from net pens for fish farming. Fisheries Science, 2006, 72(1) : 119-127. DOI: 10.1111/j.1444-2906.2006.01125.x.

[ 8 ] Porrello S, Tomassetti P, Manzueto L et al. The influence of marine cages on the sediment chemistry in the Western Mediterranean Sea. Aquaculture, 2005, 249: 145-158. DOI: 10.1016/j.aquaculture.2005.02.042.

[ 9 ] Peng PF, Hu CQ, Yu ZH et al. Analysis of spatial-temporal variation and nutritional status of water environment in the Dapeng Cove. Journal of Tropical Oceanography, 2012, 31(2) : 110-117. [ 彭鹏飞, 胡超群, 于宗赫等. 大鹏澳海水鱼 类网箱养殖区水环境的时空变化及营养状态分析. 热带海洋学报, 2012, 31(2): 110-117.]

[10] Li Y, Feng ZH. Assessment on distribution and pollution of heavy metals in shrimp culture areas of Lianyungang. Oceanologia et Limnologia Sinica, 2013, 44(6)：1457-1461. [李玉, 冯志华. 连云港对虾养殖区表层沉积物重金属污染评 价. 海洋与湖沼, 2013, 44(6) : 1457-1461.] 
[11] Deng F, Yan QP, Huang WQ et al. Bacterial composition in large yellow croaker (Larimichthys crocea) culture water. Journal of Fishery Sciences of China, 2014, 21(6): 1277-1288. [邓霏, 鄢庆枇, 黄伟卿等. 大黄鱼网箱养殖水体的 细菌群落结构. 中国水产科学, 2014, 21(6): 1277-1288.]

[12] Ma A, Liu XS, Li L et al. A comparative study on community characteristics of macrofauna inside and outside Manila clam culture waters, Jiaozhou Bay. Transaction of Oceanology and Limnology, 2014, (1): 122-128. [麻鳌, 刘晓收, 李梁等. 胶州湾菲律宾蛤仔养殖水域内外大型底栖动物群落特征的比较研究. 海洋湖沼通报, 2014, (1): 122-128.]

[13] Wang ML, Liu JJ. The impact of cage fish-farming on the aquatic environment in Poyang Lake, China: A case study of Duchang water area. Environmental Chemistry, 2019, 38(10): 2348-2355. [王毛兰, 刘景景. 鄱阳湖网箱养殖对水环 境的影响一以都昌水域为例. 环境化学, 2019, 38(10): 2348-2355.]

[14] Jiang ZJ, Fang JG, Mao YZ et al. Identification of aquaculture-derived organic matter in the sediment associated with coastal fish farming. Journal of Fishery Sciences of China, 2012, 19(2): 348-354. [蒋增杰, 方建光, 毛玉泽等. 海水 鱼类网箱养殖水域沉积物有机质的来源甄别. 中国水产科学, 2012, 19(2): 348-354.]

[15] Pi K, Zhang M, Li GC et al. Carbon and nitrogen stable isotopes as tracers to source artificial organic matter of sedimentary particle in grass carp and yellow catfish polycultured ponds. Acta Hydrobiologica Sinica, 2014, 38(5): 929-937. [皮坤， 张敏, 李庚辰等. 人工饵料对主养黄颡鱼和主养草鱼池塘沉降颗粒有机质贡献的同位素示踪. 水生生物学报, $2014,38(5)$ : 929-937.]

[16] Gu YG, Ouyang J, Ning JJ et al. Distribution and sources of organic carbon, nitrogen and their isotopes in surface sediments from the largest mariculture zone of the eastern Guangdong Coast, South China. Marine Pollution Bulletin, 2017, 120(1/2) : 286-291. DOI: 10.1016/j.marpolbul.2017.05.013.

[17] Wang ML, Lai JP, Hu KT et al. Compositions and sources of stable organic carbon and nitrogen isotopes in surface sediments of Poyang Lake. China Environmental Science, 2014, 34(4): 1019-1025. [王毛兰, 赖建平, 胡珂图等. 鄱阳湖 表层沉积物有机碳、氮同位素特征及其来源分析. 中国环境科学, 2014, 34(4) : 1019-1025.]

[18] Amir M, Paul D, Samal RN. Sources of organic matter in Chilika lagoon, India inferred from stable C and N isotopic compositions of particulates and sediments. Journal of Marine Systems, 2019, 194: 81-90. DOI: 10.1016/j. jmarsys.2019. 03.001 .

[19] Wang L. The largest cage aquaculture base in Poyang lake area was built in Duchang County, Jiangxi Province. Modern Fisheries Information, 2011, 26(10)：33. [旺罗. 江西都昌县建成鄱阳湖区最大网箱养殖基地. 现代渔业信息, $2011,26(10): 33$.

[20] Farewell to cage culture in Poyang Lake. 2018-06-04. http://www.nongcun5.com/news/20180604/57173.html. [ 鄱阳湖 告别网箱养鱼. 2018-06-04.]

[21] Wang YM, Xie Q, Xu QQ et al. Mercury bioaccumulation in fish in an artificial lake used to carry out cage culture. Journal of Environmental Sciences, 2019, 78: 352-359. DOI: 10.1016/j.jes.2018.11.016.

[22] Xie Q, Qian LS, Liu SY et al. Assessment of long-term effects from cage culture practices on heavy metal accumulation in sediment and fish. Ecotoxicology and Environmental Safety, 2020, 194: 110433. DOI: 10.1016/j.ecoenv.2020.110433.

[23] Kendall C, Silva SR, Kelly VJ. Carbon and nitrogen isotopic compositions of particulate organic matter in four large river systems across the United States. Hydrological Processes, 2001, 15(7) : 1301-1346. DOI: 10.1002/hyp.216.

[24] Lu FY, Liu ZQ, Ji HB. Carbon and nitrogen isotopes analysis and sources of organic matter in the upper reaches of the Chaobai River near Beijing, China. Science China: Earth Sciences, 2012, 42(12): 1912-1922. [卢凤云, 刘竹青, 季宏 兵. 潮白河上游有机质的碳、氮稳定同位素分析及来源探讨. 中国科学: 地球科学, 2012, 42(12): 1912-1922.]

[25] Tiessen H, Stewart JWB, Hunt HW. Concepts of soil organic matter transformations in relation to organic mineral particle size fractions. Plant and Soil, 1984, 76(1) : 287-295. DOI: 10.1007/bf02205587.

[26] Parton WJ, Schimel DS, Cole CV et al. Analysis of factors controlling soil organic matter levels in Great Plains grasslands. Soil Science Society of America Journal, 1987, 51(5) : 1173-1179. DOI : 10.2136/sssaj1987.03615995005100050015x.

[27] Redfield AC, Ketchum BH, Rechards FA. The influence of organisms on the composition of seawater//Hill MN ed. The composition of seawater, comparative and descriptive oceanography. New York: Wiley Interscience, 1963: 26-77.

[28] LaZerte BD. Stable carbon isotope ratios: Implications for the source of sediment carbon and for phytoplankton carbon assimilation in Lake Memphremagog Quebec. Canadian Journal of Fisheries and Aquatic Sciences, 1983, 40(10): 16581666. DOI: $10.1139 /$ f83-192. 
[29] Onstad GD, Canfield DE, Quay PD et al. Sources of particulate organic matter in rivers from the continental USA: Lignin phenol and stable carbon isotope compositions. Geochimica et Cosmochimica Acta, 2000, 64(20) : 3539-3546. DOI: 10. 1016/S0016-7037 ( 00 ) 00451-8.

[30] Boutton TW. Stable isotope ratios of natural materials: II. Atmospheric, terrestrial, marine, and freshwater environments// Coleman DC, Fry B eds. Carbon isotope techniques. New York: Academic Press, 1991: 173-185.

[31] Goñi MA, Teixeira MJ, Perkey DW. Sources and distribution of organic matter in a river-dominated estuary ( Winyah Bay, SC, USA). Estuarine, Coastal and Shelf Science, 2003, 57 (5/6): 1023-1048. DOI: 10. 1016/S0272-7714 ( 03 ) 00008-8.

[32] Thorp JH, Delong MD, Greenwood KS et al. Isotopic analysis of three food web theories in constricted and floodplain regions of a large river. Oecologia, 1998, 117(4) : 551-563. DOI: 10.1007/s004420050692.

[33] Schlacher TA, Wooldridge TH. Origin and trophic importance of detritus-evidence from stable isotopes in the benthos of a small, temperate estuary. Oecologia, 1996, 106(3) : 382-388. DOI: 10.1007/BF00334566.

[34] Zanden MJV, Rasmussen JB. Primary consumer $\delta^{13} \mathrm{C}$ and $\delta^{15} \mathrm{~N}$ and the trophic position of aquatic consumers. Ecology, $1999, \mathbf{8 0}(4)$ : 1395-1404.

[35] Hamilton SK, Lewis Jr WM. Stable carbon and nitrogen isotopes in algae and detritus from the Orinoco River floodplain, Venezuela. Geochimica et Cosmochimica Acta, 1992, 56(12) : 4237-4246. DOI: 10.1016/0016-7037(92)90264-j.

[36] Middelburg JJ, Nieuwenhuize J. Carbon and nitrogen stable isotopes in suspended matter and sediments from the Schelde Estuary. Marine Chemistry, 1998, 60(3/4) : 217-225. DOI: 10.1016/S0304-4203(97) 00104-7.

[37] Owen RB, Lee R. Human impacts on organic matter sedimentation in a proximal shelf setting, Hong Kong. Continental Shelf Research, 2004, 24(4/5) : 583-602. DOI: 10.1016/j.csr.2003.11.004.

[38] Wada E, Hattori A eds. Nitrogen in the sea: Forms, abundances, and rate processes. Florida: Boca Raton CRC Press, 1991: 208.

[39] Canuel EA, Cloern JE, Ringelberg DB et al. Molecular and isotopic tracers used to examine sources of organic matter and its incorporation into the food webs of San Francisco Bay. Limnology and Oceanography, 1995,40 (1) : 67-81. DOI: 10. 4319/lo.1995.40.1.0067.

[40] Phillips DL. Mixing models in analyses of diet using multiple stable isotopes: A critique. Oecologia, 2001, 127(2) : 166170. DOI: $10.1007 / \mathrm{s} 004420000571$.

[41] Cromey CJ, Nickell TD, Black KD. DEPOMOD-modelling the deposition and biological effects of waste solids from marine cage farms. Aquaculture, 2002, 214: 211-239. DOI: 10.1016/s0044-8486(02)00368-x.

[42] Pérez OM, Telfer TC, Beveridge MCM et al. Geographical information systems (GIS) as a simple tool to aid modelling of particulate waste distribution at marine fish cage sites. Estuarine, Coastal and Shelf Science, 2002, 54(4): 761-768. DOI: $10.1006 /$ ecss.2001.0870.

[43] Gondwe MJ, Guildford SJ, Hecky RE. Tracing the flux of aquaculture-derived organic wastes in the southeast arm of Lake Malawi using carbon and nitrogen stable isotopes. Aquaculture, 2012, 350/351/352/353: 8-18. DOI: 10.1016/j.aquaculture.2012.04.030.

[44] Zhuo HL, Shen PY, Wu XF. Preliminary calculations on residual feed and faeces of Lateo labrax japonicus cultured in the net cages in Xiangshan Bay. Journal of Shanghai Fisheries University, 2007, 16(5): 443-447. [卓华龙, 沈庞幼, 吴雄 飞. 象山港网箱养殖鲇鱼残饵和排粪情况初步研究. 上海水产大学学报, 2007, 16(5) : 443-447.]

[45] Seymour EA, Bergheim A. Towards a reduction of pollution from intensive aquaculture with reference to the farming of salmonids in Norway. Aquacultural Engineering, 1991, 10(2) : 73-88. DOI: 10.1016/0144-8609(91)90001-Z. 